\title{
Slow saccadic eye movements in Wilson's disease
}

\author{
TREVOR H. KIRKHAM ${ }^{1}$ AND DAVID F. KAMIN ${ }^{2}$ \\ From The National Hospital, Queen Square, London
}

SYNOPSIS This is the first reported case of Wilson's disease where a global defect of saccadic eye movements has been documented by electro-oculography. The defect of rapid eye movements is discussed in relation to current anatomical, pathological, and experimental work relating to the descending frontobulbar saccadic eye movement system. It is suggested that the caudate nucleus pathology in Wilson's disease might be responsible for the defect of saccadic movement by interrupting a descending polysynaptic pathway.

Abnormalities of ocular movements have rarely been described in Wilson's disease; indeed, their absence was stressed by Wilson (1912). This report concerns a patient with Wilson's disease in whom there was a total loss of saccadic eye movements but with preservation of smooth pursuit movements.

\section{CASE REPORT}

A 22 year old white male (A43580) suffering from Wilson's disease was admitted to the National Hospital because of deterioration of his neurological status despite treatment with penicillamine.

Intellectual and physical development had been normal until the age of 13 years when progressive difficulty with gait and performance of fine manual tasks commenced. Investigation was precipitated by a fall downstairs at the age of 17 years, and he was first examined at the National Hospital in 1968. At that time he was noted to have a fixed facial expression, speech difficulty, general rigidity, and a tremor of the arms which was worsened by purposeful movement. Kayser-Fleischer rings were present. The ocular mevements were reported as normal apart from deficient convergence. There was no family history of Wilson's disease.

Laboratory evaluation showed a serum copper of $50 \mu \mathrm{g} / 100 \mathrm{ml}$. and caeruloplasmin of $9.9 \mathrm{mg} / 100 \mathrm{ml}$. The 24 hour urinary copper excretion averaged 800 $\mu \mathrm{g}$ in a urinary volume of $2,400 \mathrm{ml}$. Normal values are: serum copper $85-115 \mu \mathrm{g} / 100 \mathrm{ml}$.; caeruloplasmin $20-35 \mathrm{mg} / 100 \mathrm{ml}$.; 24 hour urinary copper excretion 0-50 $\mu \mathrm{g}$ (Cumings, 1968). There was no

1 Address for reprints: Eye Department, The Children's Hospital, Tupper Street, Montreal, Canada.

2 Fellow, Jules Stein Eye Institute, U.C.L.A. Los Angeles, California. aminoaciduria. Liver biopsy showed a normal histological pattern.

Neuro-ophthalmic examination in May 1970 showed the ocular movements to be normal apart from absent convergence. In January 1971 elevation of the eyes was noted to be limited.

By October 1972 the patient could not walk or eat unaided. The facial expression was fixed with the mouth held open and occasional abnormal facial movements occurred. Speech was almost unintelligible and tongue movements diminished. Limb posture was dystonic and coarse, irregular movements occurred on attempted purposeful movement. Muscle tone was generally increased with features of extrapyramidal rigidity. Intelligence appeared normal.

OCULAR EXAMINATION Visual acuity, pupillary reactions, visual fields, and fundi were normal. There was no slit lamp or gonioscopic evidence of Kayser-Fleischer rings and the lenses were normal.

OCULAR MOVEMENTS 1. LID MOVEMENTS Blinking was infrequent but there were no abnormal lid movements.

2. SMOOTH PURSUIT Following movements occurred smoothly in all directions. The range of horizontal movements and of depression was normal but there was only $15^{\circ}$ of elevation. No nystagmus occurred on extreme versions. Attempts at tracking a target at a velocity in excess of $45^{\circ} / \mathrm{sec}$ did not produce any corrective saccades.

3. CONVERGENCE There was absence of convergence, but he was able to read a newspaper using a stand at a metre from the eyes without diplopia. During reading no saccadic movements were observed. 
4. SACCADIC MOVEMENTS a. Voluntary movements Horizontal voluntary movements were of normal amplitude but were extremely slow and the patient compensated by turning his head in the required direction.

There was complete absence of elevation. Depression was of full range but slow. Prominent head movements occurred to compensate for the defect of elevation.

Peak angular velocities of eye movements during horizontal ocular saccades were measured by electrooculography. The apparatus used has been described by Hood (1968). Saccadic movements were made to targets $30^{\circ}$ to each side of a midline target. Average velocities in degrees per second were:

\section{Saccades to right \\ Left to midline LE 250 RE 105 \\ Midline to right LE 230 RE 140 \\ Saccades to left \\ Right to midline LE 180 RE 200 \\ Midline to left LE 145 RE 225}

These results show that saccadic movements are excessively slow. (Using this technique we have found the average normal saccadic velocity to be $400-600^{\circ} / \mathrm{sec}$.)

b. Optokinetic responses A following movement in the direction of rotation of the drum occurred but there was no corrective saccadic movement. Both horizontal and vertical systems were involved.

c. Caloric responses Cold caloric stimulation of the labyrinth produced tonic ipsilateral deviation of the eyes but no fast movements occurred.

5. BELL'S PHENOMENON No deviation of the eyes occurred.

6. DOLL'S HEAD MOVEMENTS A full range of ocular movement in both horizontal and vertical directions (including elevation) was easily obtained on rapid head rotation.

\section{DISCUSSION}

There is strong clinical (Hoyt and Daroff, 1971) and experimental (Robinson and Fuchs, 1969) evidence that saccadic movements are generated in the frontal cortex and that smooth pursuit movements originate in the occipital cortex. The exact anatomical pathways concerned with the supranuclear control of saccadic and smooth pursuit movements are still unknown, but it is believed that the corticobulbar pathway from the frontal cortex is grouped in the anterior limb of the internal capsule and passes along the ventrolateral surface of the thalamus through the zona incerta and fields of Forel to reach the pontine paramedian reticular formation (Brucher, 1966).

Bilateral disruption of the descending frontobulbar pathway, while sparing the occipitomesencephalic pathway, produces loss of all horizontal saccadic movement and preserves the smooth pursuit movements, vergence, the slow phase of vestibular nystagmus and oculocephalic reflexes. Hoyt and Daroff (1971) used the term 'global saccadic paralysis' to indicate total loss of saccadic movements including voluntary movement, loss of the fast phases of optokinetic and vestibular nystagmus, and loss of the rapid eye movement phase of sleep. These authors noted that vertical saccadic movements are also defective in most cases.

Starr (1967) provided an example of dissociation of the saccadic from the smooth pur suit system in his study of Huntington's chorean when he demonstrated global saccadic paralysi in three of his nine patients. The cerebral lesions of Huntington's chorea involve chiefly atrophy of the caudate nucleus, putamen, and globus pallidus with reactive gliosis, and similar diffuse changes occur in the cerebral cortex, particularlys the frontal lobes (McCaughey, 1961). The pathological degeneration in Wilson's disease is similar to that in Huntington's chorea. The brunt of the damage is again borne by the putamen, globus pallidus, and caudate nucleus and widespread cortical damage has been described (Hadfield, 1923; Schulman and Barbeau, 1963).

Goldberg and Von Noorden (1966) made an electro-oculographic study of eight patients with Wilson's disease who had moderate to severe neurological damage. All eight had normal saccadic velocities during horizontal saccades and had normal optokinetic responses.

Because of the generalized muscular rigidity and the widespread nature of the pathologically demonstrated cerebral lesions Walsh and Hoyt (1969) commented that the absence of oculomotor system involvement in Wilson's disease was surprising. In the patient reported by Hadfield (1923) it was noted that there was only a flicker of both eyes in the required direction in response to command; pathologically there were 
extensive lesions in the frontal cortex. Heine (1933) described a patient with paralysis of upward gaze. Richter (1948) emphasized that in Wilson's disease the frontal cortex is usually more severely affected than other cortical areas and that the lesions in the basal ganglia tend to be bilateral and symmetrical. He described a patient who had difficulty with conjugate gaze both horizontally and upwards. These cases probably represent examples of global saccadic paralysis and demonstrate the clinicopathological correlation of interruption of the frontobulbar oculomotor pathway.

The clinical and biochemical data obtained in the present patient support the diagnosis of Wilson's disease. The patient made prominent compensatory head thrusts during attempted willed saccades and electro-oculography confirmed impaired ability to generate a saccadic movement.

Therefore, it is apparent that global saccadic paralysis may be an occasional feature of both Wilson's disease and Huntington's chorea. Starr (1967) suggested that the caudate nucleus might be intimately related to the saccadic eye movement system and the possibility that subcortical structures could initiate voluntary eye movements is discussed by Troost et al. (1972).

Electro-oculographic recordings (Dix et al., 1971) have confirmed defective saccadic eye movements in progressive supranuclear ophthalmoplegia, where the pathology affects neurones rather than axons (Steele et al., 1964) and abnormalities, particularly of vertical gaze, have been stressed in patients with lipid storage disease (Sanders and Wybar, 1970; Grover and Naiman, 1971; Neville et al., 1973). There is mounting evidence that the descending frontobulbar saccadic pathway may be polysynaptic. This is suggested by the anatomical studies of Astruc (1971) and by the conflicting results of studies on delay in the oculomotor system (Robinson and Fuchs, 1969; Zuber, 1969). The distribution of the lesions in Steele, Richardson, Olszewski syndrome and in Huntington's chorea and Wilson's disease, in all of which there may be progressive, symmetrical, bilateral slowing of saccadic eye movements may be further supportive evidence for the concept of a polysynaptic pathway. Clearly therefore destruction of the polysynaptic frontobulbar pathways concerned with saccadic eye movements may occur in any chronic neurological disease where widespread cerebral pathology occurs. Future studies of patients with Wilson's disease will probably reveal further examples of defective saccadic movements.

The marked deficiency of convergence in the present patient deserves comment. Vergence may be organized within the occipital cortex via connections across the corpus callosum (Westheimer and Mitchell, 1969; Mitchell and Blakemore, 1970). Conceivably minimal lesions within the occipital cortex or descending occipitomesencephalic pathways could disrupt vergence without interfering with smooth pursuit movements. The main stimulus to vergence movement must be considered to be a voluntary input which renders interpretation of observed movements difficult. The explanation for the loss of convergence in the present patient must therefore remain an open question.

We thank Dr. K. J. Zilkha for permission to study his patient, Dr. J. D. Hood and Mr. J. Leech of the MRC Hearing and Balance Unit for the electrooculographic recordings, and Miss Josephine Lace for secretarial assistance.

\section{REFERENCES}

Astruc, J. (1971). Corticofugal connections of area 8 (fronta eye field) in Macaca mulatta. Brain Research, 33, 241-256.

Brucher, J. M. (1966). The frontal eye field of the monkey. International Journal of Neurology (Montevideo), 5, 262281.

Cumings, J. N. (1968). Biochemistry of the basal ganglia. In Handbook of Clinical Neurology, vol. 6, p. 118. Edited by P. J. Vinken and G. W. Bruyn. North-Holland: Amsterdam.

Dix, M. R., Harrison, M. J. G., and Lewis, P. D. (1971). Progressive supranuclear palsy (the Steele-RichardsonOlszewski syndrome). A report of 9 cases with particular reference to the mechanism of the oculomotor disorder. Journal of Neurological Sciences, 13, 237-256.

Goldberg, M. F., and Von Noorden, G. K. (1966). Ophthalmologic findings in Wilson's hepatolenticular degeneration with emphasis on ocular motility. Archives of Ophthalmology, 75, 162-170.

Grover, W. D., and Naiman, J. L. (1971). Progressive paresis of vertical gaze in lipid storage disease. Neurology (Minneap.), 21, 896-899.

Hadfield, G. (1923). On hepato-lenticular degeneration, with the account of a case and the pathological findings. Brain, 46, 147-178.

Heine, L. (1933). Über Augenveränderungen bei Pseudosklerose. Kayser-Fleischer-Ring. Pupillen- und Akkomodationsstörung. Blickhebungslahmung. Klinische Monatsblätter für Augenheilkunde, 91, 433-437.

Hood, J. D. (1968). Electro-nystagmography. Journal of Laryngology and Otology, 82, 167-183.

Hoyt, W. F., and Daroff, R. B. (1971). Supranuclear disorders of ocular control systems in man. In The Control of 
Eye Movements, pp. 175-235. Edited by P. Bach-y-Rita, C. C. Collins, and J. E. Hyde. Academic Press: New York. McCaughey, W. T. E. (1961). The pathologic spectrum of Huntington's chorea. Journal of Nervous and Mental Disease, 133, 91-103.

Mitchell, D. E., and Blakemore, C. (1970). Binocular depth perception and the corpus callosum. Vision Research, 10, 49-54.

Neville, B. G. R., Lake, B. D., Stephens, R., and Sanders, M. D. (1973). A neurovisceral storage disease with vertical supranuclear ophthalmoplegia, and its relationship to Niemann-Pick disease. A report of nine patients. Brain, 96, 97-120.

Richter, R. (1948). The pallial component in hepatolenticular degeneration. Journal of Neuropathology and Experimental Neurology, 7, 1-18.

Robinson, D. A., and Fuchs, A. F. (1969). Eye movements evoked by stimulation of frontal eye fields. Journal of Neurophysiology, 32; 637-648.

Sanders, M. D., and Wybar, K. C. (1970). Vertical supranuclear ophthalmoplegia with compensatory head movements. In Transactions of the Consilium Europaeum Strabismi Studio Deditum Congress, London, 1969. Pp. 63-69. Kimpton: London.
Schulman, S., and Barbeau, A. (1963). Wilson's disease: a case with almost total loss of cerebral white matter. Journal of Neuropathology and Experimental Neurology, 22, 105-119.

Starr, A. (1967). A disorder of rapid eye movements in Huntington's chorea. Brain, 90, 545-564.

Steele, J. C., Richardson, J. C., and Olszewski, J. (1964). Progressive supranuclear palsy. A heterogenous degeneration involving the brain stem, basal ganglia and cerebellum with vertical gaze and pseudobulbar palsy, nuchal dystonia and dementia. Archives of Neurology, 10, 333-359.

Troost, B. T., Weber, R. B., and Daroff, R. B. (1972). Hemispheric control of eye movements. 1. Quantitative analysis of refixation saccades in a hemispherectomy patient. Archives of Neurology, 27, 441-448.

Walsh, F. B., and Hoyt, W. F. (1969). Clinical NeuroOphthalmology, 3rd edn, vol. 2, p. 1038. Williams and Wilkins: Baltimore.

Westheimer, G., and Mitchell, D. E. (1969). The sensory stimulus for disjunctive eye movements. Vision Research, 9, 749-755.

Wilson, S. A. K. (1912). Progressive lenticular degeneration: a familial nervous disease associated with cirrhosis of the liver. Brain, 34, 295-509. 